\title{
EL SUFRAGIO UNIVERSAL EN ESPAÑA: CAUSAS Y EFECTOS
}

\author{
CARLOS DARDÉ
}

El objeto de la presente intervención es considerar las causas y, sobre todo, los efectos de la ley de sufragio universal de 1890, para la vida política española, desde su aprobación hasta la caída de la monarquía parlamentaria en 1931.

No era la primera vez que en España se aplicaba el sufragio universal masculino. Como se sabe, el triunfo de la revolución de 1868 supuso también el de las tesis democráticas sobre la constitución del Estado. Las cinco elecciones celebradas durante el Sexenio, 1868-1874, lo fueron con sufragio universal, lo mismo que las primeras de la Restauración, de 1876, que Cánovas decidió fueran llevadas a cabo de acuerdo con la legislación existente. Todas ellas fueron ganadas, por amplia mayoria, por el partido que las había convocado y organizado. No pretendo, sin embargo, hacer ninguna comparación entre estas elecciones y las celebradas durante la Restauración, 1875-1931, porque el Sexenio y la Restauración son situaciones históricas sustancialmente diferentes, especialmente por lo que refiere al sistema político, lo que hace muy problemática su comparación. Tampoco me referiré a la práctica del sufragio universal durante la II República, en este caso también femenino, porque igualmente las situaciones históricas y el sistema político de ambos períodos eran, si cabe, todavía más diferentes que en el caso anterior.

La comparación que quiero establecer es dentro de la misma Restauración, entre los períodos con sufragio restringido y con sufragio universal. Concretamente, el problema que quiero considerar es en qué medida la vida política y el comportamiento electoral del período 1875-1890, durante la mayor parte del cual existió el sufragio censitario, fueron afectados por la introducción del sufragio universal y cuáles fueron las consecuencias de esta ley para la evolución posterior del sistema político de la Restauración.

La carencia del número suficiente de buenos estudios sobre aspectos fundamentales de la vida política española durante esta época, como, por ejemplo, las bases sociales de los partidos, o explicaciones coherentes del comportamiento electoral y su evolución referidas a áreas geográficas concretas, hace que la contestación a una pregunta de este tipo sea necesariamente provisional, una hipótesis de trabajo basada en algunos indicadores disponibles, más que una conclusión sólidamente establecida sobre conocimientos ciertos. 
El esquema que seguiré es considerar en primer lugar las caracteristicas de la vida política y del comportamiento electoral durante el período 18751890 , para continuar con las razones de la aprobación de la ley del sufragio universal y el significado que para sus autores tenía esta medida, y concluir con los efectos que se derivaron de su aplicación a partir de 1891.

1. Durante el período $1875-1890$, todos los partidos políticos, tanto los monárquicos como los republicanos, tuvieron un programa político con contenido, con coherencia ideológica; en este aspecto no se les puede atribuir la vaciedad y la artificiosidad con que habitualmente se caracteriza en conjunto a los partidos políticos de la Restauración.

Con la Restauración, Cánovas, como es bien sabido, pretendió y consiguió, construir un nuevo sistema político; no quería una simple vuelta a la situación anterior a la revolución del 68 , la del reinado de Isabel II, caracterizada por el exclusivismo de partido. Los pilares sobre los que asentó el nuevo sistema fueron la Constitución de 1876, la alternancia de partidos en el ejercicio del poder y, como consecuencia, el alejamiento de los militares de la política, ya que su concurso dejó de ser imprescindible para el acceso al poder. La Constitución de 1876, a pesar del principio doctrinario en que se asentaba - la soberanía compartida por las Cortes con el Rey-, podía ser admitida sin excesivos problemas por todos los partidos monárquicos ya que, además de establecer la libertad religiosa, dejaba indeterminadas la mayor parte de las principales cuestiones políticas, permitiendo así a cada partido gobernar de acuerdo con sus principios. La alternancia de partidos debía de ser arbitrada por la Corona, que se convirtió de esta manera en la verdadera fuente del poder; un gobierno recibia el encargo de realizar las elecciones que siempre le habían de proporcionar una amplia mayoría de votos, gracias a una serie de mecanismos que llamamos "caciquiles", cuya verdadera naturaleza estamos lejos de conocer. El sistema no era democrático, pero fue el procedimiento ideado -el único considerado posible dado el grado de desarrollo económico y cultural d el país- para evitar el exclusivismo de partido y permitir la existencia de un régimen liberal estable. Este proyecto, en la conservadora Europa de los años setenta del siglo pasado, no era en absoluto reaccionario y para hacerlo realidad, Cánovas tuvo que crear un nuevo partido, el conservador, y luchar un duro combate con la derecha más dura, los moderados, a quienes terminó derrotando (1).

La política entre los liberales no tuvo tampoco nada de artificial en el período en el período 1875-1890. Tuvieron que tomar resoluciones decisivas sobre cuestiones importantes, como la aceptación de la monarquía, cuando algunos habían participado activamente en las instituciones republicanas; la constitución de 1876, en lugar de la de 1869, cuyo restablecimiento propuso 
Sagasta en los primeros momentos de la Restauración; y el turno de los partidos, basado en el arbitraje de la Corona. A lo largo de diez años tuvo lugar el proceso de formación del que habría de ser el partido liberal de la monarquía, proceso que culminó con la formulación de un programa, en junio de 1885 , que comprendía, entre otras medidas, el sufragio universal, el jurado, y un procedimiento para la reforma constitucional; ésto suponía de hecho la recuperación para el nuevo régimen del ideario democrático de la revolución de 1868, y de buena parte de los políticos que habían participado en ella. El nuevo partido nacía con el liderazgo de Sagasta. Durante la situación liberal presidida por éste entre 1885 y 1890 , la mayor parte del programa liberal fue aprobado por las Cortes y se convirtió en ley. El sufragio universal fue una de las medidas aprobadas.

Los partidos republicanos, por último, también tuvieron, durante el período 1875-1890, un significado ideológico preciso, aunque variado según la personalidad y la trayectoria de sus líderes: Castelar, el más conservador, impulsor de las reformas democráticas propuestas por el partido liberal; Pi y Margall, en el extremo opuesto, que propugnaba la constitución federal del Estado, con un partido que tenía una considerable implantación popular; y Salmerón y Ruiz Zorrilla, patrocinadores de distintos proyectos reformistas, a los que terminó separando la voluntad de este último de recurrir a la conspiración militar como medio para conseguir la implantación de la república.

Por tanto, a lo largo de los primeros quince años de la Restauración, determinadas cuestiones fundamentales estuvieron en el primer plano de la vida política, caracterizando y diferenciando a los partidos: entre ellas, los derechos y las libertades individuales, la democracia, la forma de gobierno, el recurso al ejército como medio de cambio político, la actitud hacia determinados episodios controvertidos de la historia reciente, como la revolución de 1868. Además de la polémica librecambismo-proteccionismo, que fue dejada fuera de la disciplina de los partidos, pero que estuvo continuamente presente.

Afirmar lo precedente no quiere decir, sin embargo, que estas cuestiones fueran las que determinaran siempre el comportamiento electoral de la mayor parte de la población durante los años considerados. Pero sí que, durante los mismos, la política no tenía el carácter surrealista que con frecuencia se le atribuye y que, para aquellas personas interesadas en la misma, había cuestiones que hacían que vieran con mayor o menor simpatía a determinados partidos y, en caso de tener posibilidad, otorgaran el voto a unos o a otros. En fin, que no resulta inadmisible un cierto componente ideológico, o de opinión, en el comportamiento electoral, sobre todo cuando el censo electoral quedó reducido, por la ley de 1878, a un 5\% aproximadamente de 
la población, es decir, a uno de cada cinco varones mayores de 25 años. Censo determinado por el pago de una elevada contribución directa o por la acreditación de determinadas capacidades.

Desde luego, un comportamiento como el registrado en las elecciones de $1879,1881,1884$ y 1886 - con abrumadoras mayorías para el partido que las organizó, conservador y fusionista o liberal, alternativamente- no es explicable contando exclusiva ni primordialmente con la opinión. Es absolutamente ilógico que se produjeran cambios tan radicales, y de forma tan regular, en la forma de pensar de los electores, sobre todo cuando los partidos pretendían tener un significado ideológico tan contrastado. No es fácil, sin embargo, determinar y jerarquizar los medios a través de los cuales los candidatos gubernamentales conseguían imponerse de forma tan contundente. Estudios recientes han puesto de manifiesto la variedad de procedimientos que han recibido el nombre de "caciquiles»: el «encasillado» o designación como candidato oficial por parte del ministerio, el peso de la influencia personal o familiar del candidato, el fraude gracias a la indiferencia general, o la compra de votos, entre otros. Son necesarios estudios locales que ponderen la influencia de cada uno de ellos en cada una de las unidades electorales. No obstante, a través del estudio a escala nacional de las convocatorias electorales, cabe obtener algunas ideas sobre la importancia de los citados procedimientos en momentos determinados.

Concretamente, en las elecciones de 1886, celebradas por el partido liberal, el «encasillado», la presión gubernamental, el fraude y la compra de votos no parecen haber tenido una importancia decisiva en la mayor parte de los casos, destacando, por el contrario, el peso de la influencia personal de cada uno de los candidatos en sus respectivos distritos.

En efecto, la idea del «encasillado» que nos transmite una parte de la historiografía de la Restauración, como un plan preciso para el reparto de los escaños, elaborado por el partido en el gobierno de acuerdo con los de la oposición, como si todos fueran organizaciones fuertemente centralizadas y eficientes, no es confirmada por la realidad de las elecciones de 1886; en aquel año, más de cien candidatos del partido liberal en el gobierno se enfrentaron entre sí, sin el reconocimiento de ministeriales; las oposiciones, en unos 150 distritos y circunscripciones, un $30 \%$ aproximadamente del total, no aceptaron el supuesto pacto y presentaron batalla al gobierno, llegando incluso en algunos casos a enfrentarse mutuamente.

La presión gubernamental fue mucho menor que la ejercida en otras ocasiones, y así lo reconoció la oposición. En quince provincias no se ejerció acción alguna - suspensión o celebración parcial de elecciones- contra ningún Ayuntamiento y en otras veintisiete provincias, estas medidas afectaron 
a menos de diez Ayuntamientos. La actuación de los gobernadores civiles fue más respetuosa con el ejercicio de las libertades públicas y en el Tribunal de Actas Graves, organismo del Congreso de los Diputados donde se juzgaban las elecciones sobre las que se habían presentado reclamaciones de importancia, sólo tres gobernadores - los de Valencia, Barcelona y Orensefueron denunciados por las presiones ejercidas sobre los alcaldes de tres distritos.

El fraude electoral, por otra parte, aparece como importante, aunque limitado, y sin que quepa atribuirle, en la inmensa mayoría de los casos, el resultado de la elección: de acuerdo con las impugnaciones presentadas, no afectó en absoluto a más de la mitad de los distritos y circunscripciones, y en aquellos donde hubo denuncias, el $43,1 \%$, éstas se referían sólo a un pequeño número de sus secciones. No obstante, la proliferación de los casos de corrupción, en sus variadas formas, la lenidad con que son juzgados por el Congreso, e incluso la misma grosería con que son realizados, sin preocupación por guardar las formas, nos hablan de la considerable extensión de los procedimientos ilegales y de la connaturalidad con los mismos. En estas elecciones, por último, no hay ninguna denuncia de compra de votos por dinero.

El principal factor explicativo del triunfo gubernamental es, como he indicado, la influencia personal de los candidatos. "Ni un solo conservador afirmaba el diario La Época se ha presentado donde no tenga fuerzas propias». Y en otra ocasión daba cuenta de que el presidente del Consejo y el ministro de Gobernación, ante las peticiones de los candidatos liberales, «contestan invariablemente que, en las próximas elecciones, no habrá candidatos ministeriales y que se sentarán en el Congreso los que por su propia influencia cuenten con más votos". ¿Cuál era la base de esta influencia? ¿El poder económico, el prestigio tradicional, el control de la máquina política? Nuevamente, son los estudios locales los que tienen que dar la respuesta. No obstante, dadas las condiciones generales de los electores con la ley de sutragio censitario - fundamentalmente su independencia económica - parece lógico pensar en una influencia basada en el acuerdo más que en la coacción, en el consentimiento más que en la violencia; es decir en la existencia de clientelas políticas en torno a uno o varios personajes locales, a los que llamamos "caciques" (2).

La interpretación del caciquismo como patronazgo político que han ofrecido, entre otros, J. Romero Maura y J. Varela Ortega, parece, por tanto, especialmente adecuada para explicar el funcionamiento del sistema político durante este período, en la mayor parte de los distritos y circunscripciones del pais, porque se corresponde mejor que otras interpretaciones con las condi- 
ciones estructurales del electorado: su carácter reducido -es más fácil satisfacer las peticiones $u$ organizar grupos de intereses en torno a pocos que a muchos- y su independencia económica. La base de la influencia de un cacique era su clientela, obtenida gracias al ejercicio arbitrario y discriminatorio de la ley en beneficio de la misma. En este caso no es necesario explicar la indiferencia o pasividad de la mayoría ya que su participación no es requerida (3).

2. Respecto a la aprobación del sufragio universal en 1890 , lo primero que cabe afirmar es que éste no fue conseguido en España por un movimiento popular, por la presión de las masas deseosas de lograr una mayor participación política, con unos objetivos determinados. No quiere esto decir que Sagasta y los demás políticos liberales no supieran que el sufragio universal satisfacía una aspiración popular, expresada en anteriores ocasiones, sino que si lo plantearon y aprobaron en el momento en que lo hicieron, sin ninguna exigencia social, fue porque suponian que, en primer término, habría de ser beneficioso para sus propios intereses políticos. Cuando Pablo Iglesias, en su Informe oral ante la Comisión de Reformas Sociales, en 1885, despreciaba los «principios progresivos» inscritos en los programas de los partidos burgueses - principios tales como el sufragio universal o la reducción de horas de trabajo- lo hacía porque «si los estampan - afirmaba - es por su propia conveniencia, por triunfar en la lucha que tienen con otros elementos tan burgueses como ellos, no porque se propongan hacer nunca nada en favor de la clase trabajadora» (4).

Precisamente los conservadores utilizaron esa falta de presión social, que interpretaban como absoluta falta de interés por la política, para oponerse a la aprobación de la ley. «A estas horas - decía el diputado Lorenzo Domínguez en la discusión del proyecto en el Congreso- en que nosotros nos ocupamos aquí de hacer la felic idad de todos los que no tienen voto hasta ahora, de esta manera tan extraña, los interesados no se han enterado siquiera de que nos estamos ocupando de hacerles felices por tan singular manera». Los liberales no podían negar esa atonía social; el futuro conde de Romanones, que iniciaba por estas fechas su carrera política, la atribuia a la forma de ser de los españoles: «¿Quién desconoce - preguntaba - que en las cuestiones políticas el carácter de España es indiferente y apático?» Canalejas reconocía el escaso interés que la sociedad mostraba por actividades políticas como las elecciones y los debates parlamentarios, y veía en ello el mayor peligro para las instituciones representativas, pero, con más espíritu crítico, consideraba que los defectos de la clase política eran los responsables del mismo y defendía el sufragio universal, precisamente, por la función que previsiblemente cumpliría de incrementar el interés social por la política. 
Entre las razones que llevarón al gobierno liberal a presentar la ley de reforma electoral, no parece muy verosímil la que se ha expuesto en alguna ocasión, de pretender contrarrestar, gracias al aumento del voto rural, un marcado declive del prestigio del partido entre el electorado urbano, a causa de diversos escándalos financieros en el Ayuntamiento de Madrid. Ni estos escándalos eran algo nuevo, ni sus posibles efectos sobre la opinión tenían repercusiones electorales significativas ya que, como hemos visto, el papel de la opinión en el comportamiento electoral era secundario. Por el contrario, si el proyecto de sufragio universal fue presentado y aprobado por las Cortes, fue por el interés que tenía Sagasta en dar cumplimiento a la mayor parte del programa liberal, con objeto de consolidar el partido formado en 1885 , y también su liderazgo sobre el mismo. Una vez aprobada la ley de asociaciones de 1887 y la que establecía el juicio por jurados para determinados delitos, el sufragio universal para la elección de diputados a Cortes -en las elecciones de ámbito provincial ya se había establecido en 1882- era la única medida importante del programa de 1885 que quedaba pendiente, con excepción del procedimiento para la reforma constitucional que no llegaría a ser planteado.

Los elementos que habían constituido en 1885 el partido liberal eran muy variados y el trabajo de Sagasta para conciliar sus diversas tendencias no fue tarea fácil. En concreto, durante los años 1888-1890, el partido atravesó una crisis interna muy fuerte que llegó a ocasionar la salida del mismo de alguna de sus figuras más destacadas. En estas circunstancias, Sagasta encontró en el sufragio universal - principio del que personalmente no era muy partidario- un «ángel tutelar», según la expresión de Castelar (la reina regente era, para el republicano, el otro ángel con que contaba el jefe liberal). La oposición a Sagasta dentro del partido estaba protagonizada fundamentalmente por Cristino Martos, el general Cassola, y el político vallisoletano Germán Gamazo.

Es difícil encontrar otras razones que las puramente personales -y así fue destacado por los contemporáneos- en la disidencia de Martos, producida en mayo de 1889. Aunque a lo largo de su vida política no había dejado de representar proyectos de cierta envergadura, como la integración de los radicales en la I República o el intento de hacer desistir definitivamente a Ruiz Zorrilla de sus propósitos golpistas, en los momentos que estamos considerando, Martos era una figura devaluada y no constituía, en absoluto, una amenaza para la jefatura de Sagasta. El conflicto con el general Manuel Cassola tenía, por el contrario, una justificación política más clara. Este general, nombrado ministro de Guerra en 1887, había presentado una serie de reformas militares que incluían el servicio militar obligatorio y una amplia reorganización interna del ejército. Ante la cerrada oposición que presentaron a estos 
proyectos no sólo el partido conservador sino muchos altos jefes militares, Sagasta no quiso forzar la situación y, sin llegar a desautorizar al ministro, no le prestó el apoyo necesario para sacar adelante las reformas. Cassola dimitió en junio de 1888 , realizando a continuación algunas campañas críticas contra su antiguo presidente.

Mucha mayor importancia tenía el enfrentamiento interno que, a partir de 1887 , se originó a causa de la política económica del gobierno. Los temas de política económica eran tradicionalmente dejados al margen de la disciplina de los partidos; éstos se definian formalmente por sus principios específicamente políticos. Sin embargo, comparativamente, la política liberal, ya que no los principios, había sido librecambista desde 1881, cuando el partido fusionista accedió al poder, mientras que la conservadora había sido proteccionista desde 1875. El conflicto surgió cuando Germán Gamazo, al frente de un importante grupo de diputados y senadores liberales, al amparo de la libertad de opinión existente en lo económico, pretendió variar la tradicional política del partido, sustentada por Sagasta a través del nombramiento de ministros de Hacienda de orientación librecambista.

Gamazo, que era portavoz de una Liga Agraria fundada en 1887, pretendia que se adoptara una solución a la creciente falta de competitividad del trigo nacional frente al importado, problema que, como se sabe, afectaba por igual a ganaderos e industriales en sus respectivas producciones. Huía de declaraciones doctrinales; el problema, decía, era la salvación de la riqueza territorial de España. Los medios que proponía eran el abaratamiento de la producción mediante la rebaja de los impuestos que gravaban la propiedad de la tierra, el cultivo y la ganadería - aunque para equilibrar los ingresos del Estado fuera necesario implantar un impuesto general sobre la renta$y$, en segundo lugar, la protección frente al exterior, en caso necesario. Pretendía quitar significación política a sus propuestas declarándose enemigo del atomismo de los partidos, contrario a toda disidencia, y participando en los debates en favor de las reformas democráticas; presentaba la reforma fiscal de forma que pudiera ser suscrita por todo el partido, como la forma de dar cumplimiento al artículo $3 .^{\circ}$ de la Constitución de 1876, que establecía que todo español debía contribuir a los gastos del Estado en proporción a su riqueza. Sin embargo, en la práctica política era implacable, actuando de acuerdo con sus intereses y al margen de la disciplina de partido en todo lo que pudiera tener relación con la política económica como, por ejemplo, la elección de miembros de las comisiones parlamentarias. Esto creó serios problemas a Sagasta y, en una ocasión hasta una crisis de gobierno al perder éste una votación, a fines de 1888. A lo largo de 1889, el enfrentamiento fue haciéndose más intenso y preocupante para Sagasta al conseguir Gamazo que 
el general Martínez Campos, con gran influencia cerca de la regente, se alineara en su grupo, ademá de todos los disidentes. De la importancia de la crisis interna de idea el que, en enero de 1890, Alonso Martínez recibiese el encargo de formar gobierno con el partido liberal, aunque sin resultado positivo; sería la única vez que, en vida de Sagasta, sucediera una cosa semejante.

En medio de todas estas dificultades, el cumplimiento del programa histórico del liberalismo democrático era la única forma de dar al partido la cohesión necesaria y el contrapeso ideológico para que Sagasta pudiera acceder a las pretensiones proteccionistas de Gamazo - como de hecho habría de hacer una vez aprobado el sufragio universal- sin espantar a la corriente democrática del partido.

Otra razón política que abonaba la conveniencia de la aprobación del sufragio era la promesa de Castelar, si la democracia era implantada, de prestar su apoyo a la monarquía disolviendo su partido y recomendando a sus correligionarios que ingresaran en la agrupación más liberal del régimen. Por otra parte, en caso de no hacerlo, era lógico pensar que, lo mismo que en 1882 , otro partido recogería esta bandera de la democracia monárquica, privando al de Sagasta de su principal significado político. El general López Domínguez, al frente de los restos de la Izquierda Dinástica, era el mejor colocado para el relevo. «El señor Sagasta - decía el conservador Francisco Silvela en el Congreso, refiriéndose al sufragio universal- no ha tenido más objetivo que evitar la formación de una izquierda que pudiera debilitar, de cerca o de lejos, su jefatura sobre el partido liberal».

El partido conservador también contribuyó, en cierta forma, a la aprobación del sufragio. Aunque se opusieron abiertamente a él tanto en la prensa como en el Congreso -afirmando, no obstante, que lo respetarían cuando llegaran al poder - la discusión del proyecto en el Senado duró exclusivamente dos sesiones, al renunciar casi por completo a la defensa de las enmiendas presentadas. Como escribió Gabriel Maura, los conservadores tenía prisa por volver al gobierno y estaban dispuestos a facilitar las cosas para que los liberales cumplieran su programa y dejaran libre el campo.

Un problema diferente al de las causas de la aprobación del sufragio universal, aunque estrechamente relacionado con él, es el del significado que para sus autores tuvo esta medida, el «sentido de la acción» en términos weberianos. En concreto, resulta interesante conocer la dimensión real que para ellos tenía la ampliación del sufragio y los fines que perseguian, además del inmediato de reforzamiento del partido.

Los liberales de 1890 vieron en la ley de sufragio universal el punto final y la culminación del proceso de formación del sistema constitucional iniciado a principios de siglo. Consideraban que con su admisión de la Constitución 
de 1876, que recogía el principio doctrinario de que la soberanía era compartida por las Cortes con el Rey, y con la aceptación por parte de Cánovas del sufragio universal, que era la consecuencia fundamental del principio de la soberanía nacional, se llevaba a cabo la síntesis que cerraba el ciclo revolucionario de España en el siglo XIX. Pero, en la práctica, no pretendieron alterar de ningún modo el funcionamiento real del sistema, que, como hemos dicho, descansaba sobre la prerrogativa regia y no sobre la voluntad popular expresada a través de las urnas.

La argumentación de la exposición de motivos del proyecto presentado en el Congreso atiende a ambas cuestiones, doctrinal y práctica. Por una parte, afirma el sentido ideológico e histórico de la medida y, por otra, el hecho de que no venga a alterar el «equilibrio constitucional» existente, aunque no se mencione expresamente el papel de la Corona. La reflexión sobre las consecuencias prácticas, a largo plazo, del sufragio universal, sobre los problemas de su aplicación en una sociedad muy desigual, que se manifiesta en la discusión del proyecto en el Congreso, es muy escasa y superficial, entre los liberales. Para Álvaro de Figueroa no había ningún peligro para el orden burgués o el derecho de propiedad porque upor la ley providencial y por la ley de la naturaleza, la fuerza de la inteligencia y de la instrucción se impone siempre a los ignorantes, y por eso, los ignorantes, aunque siempre sean más, nunca podrán tener la misma influencia en la participación de los negocios ni en la dirección del Estado». Y según Canalejas, la ampliación del sufragio habría de ser un medio para perfeccionar efectivamente el régimen representativo. «Si las Cámaras han de ser -decía- espejos fieles de la Nación (...) forzoso es que preparemos todos nuestra educación propia para el establecimiento de este régimen. Es muy cómodo vivir con una extensión del sufragio determinada, no poner la vista en el porvenir y en la realidad (...) permanecer en el quietismo, aceptar que hay peligros y riesgos alli donde sólo hay riesgos y peligros para la propia inercia y estímulos necesarios para la actividad de los partidos políticos».

Nos encontramos, por tanto, entre los liberales, además del pragmatismo de Sagasta, con una visión tradicional de la sociedad, que considera la desigualdad y la ignorancia de la mayoría, como el orden natural de las cosas, aceptado de buen grado por los que están abajo de la escala social, y con una especie de idealismo democrático, semejante al modelo definido por C. B. Macpherson como "democracia como desarrollo", que no se plantea seriamente los problemas de la aplicación del principio «un hombre, un voto».

Los conservadores, por el contrario, en la citada discusión del proyecto, aunque a veces adoptaron un tono claramene antidemocrático y tremendista -a través del marqués de Pidal, por ejemplo- se expresaron en numerosas 
ocasiones más críticamente, poniendo de manifiesto las consecuencias que previsiblemente habria de tener la aplicación de la ley. "¿Acaso no sería preferible - se preguntaba el diputado conservador Lorenzo Domínguez- procurar que en España hubiera un verdadero cuerpo electoral, cuyas opiniones fuesen una guia para los altos poderes del Estado y aun para nosotros mismos? ¿Nadie niega ya nuestra corrupción y nuestros vicios electorales? Nadie los niega; todos los partidos están conformes y convienen en que son grandes: ¿no sería, por consiguiente, lo más cuerdo dedicarnos a corregirlos y enmendarlos en vez de traer aquí un proyecto de ley que los ha de aumentar necesariamente en proporción a la gran extensión que con él se da al voto?» En el mismo sentido, Francisco Silvela reprochaba a los liberales el que se apartaran con su política de «la sed creciente de realidad, de sinceridad, de positivismo", característica de aquel momento histórico, aconsejándoles «abandonar ese sistema funesto de crear, por meros compromisos de una opinión ficticia de Madrid, leyes tras leyes, notoriamente tan avanzadas sobre lo que las necesidades del país exigen y sobre lo que los medios y las facultades de los que van a aplicarlas han alcanzado».

No obstante, los conservadores respetaron esta legislación cuando llegaron al gobierno. Cánovas, que se había manifestado en contra del sufragio universal, declaró que no le asustaba su aplicación práctica, que, en 1876, con esa norma electoral, no había tenido problemas para asegurar el nuevo régimen político. Y, efectivamente, después de 1890, tampoco los tendría para volver a ganar las elecciones cuando, por turno, le correspondió hacerlo.

3. Los efectos de una ley como de una ley como la de sufragio universal de 1890, que tenía un significado doctrinal e histórico tan importante y que multiplicaba aproximadamente por seis el censo electoral - de unos 800.000 a algo menos de cinco millones- fueron lógicamente de gran trascendencia, tanto para el sistema de partidos como para el comportamiento electoral. Para el sistema de partidos, porque consolidó definitivamente al liberal bajo la jefatura de Sagasta, hasta la muerte de éste en 1903. Con el cumplimiento de la parte del programa histórico del liberalismo democrático que parecía factible en aquellos momentos -el sufragio universal pero no la proclamación de la soberanía nacional, que implicaba la reforma constitucional- desaparecían las posibles justificaciones para cualquier escisión a la izquierda del partido o para cualquier otra agrupación que pretendiera tener un significado democrático pero no revolucionario. Incluso los republicanos de carácter conservador, de acuerdo con la promesa de Castelar, disolvieron el partido republicano histórico o posibilista, integrándose una parte de ellos en la monarquía. Lo que ocurrió también es que este cumplimiento dejaba sin programa al partido liberal, necesitado de encontrar un nuevo horizonte para su 
acción política. Y ésto no ocurrió. La pérdida de contenido ideológico que es generalmente atribuida a los partidos de la Restauración, es clara en el partido liberal a partir de esta fecha. Tampoco ocurrió la transformación de la estructura de los partidos, ni del liberal ni del conservador, que siguieron siendo «partidos de notables», agrupaciones artificiales en torno a unos pocos personajes locales. No fue promovido ningún tipo de organización de base que sirviera para captar el voto de los ciudadanos a quienes se acababa de transferir el derecho electoral, desde luego porque no fue considerado necesario; estas organizaciones tampoco surgieron espontáneamente en torno a cualquier problema determinado.

Con la nueva ley, los resultados electorales siguieron siendo tan favorables para el partido que organizaba las elecciones, de acuerdo con el encargo de la Corona, como lo habían sido antes. En algunas grandes ciudades - Madrid, Barcelona, Valencia - sí cambiaron efectivamente las cosas: la representación republicana fue más numerosa y constante, llegando en ocasiones a ocupar el lugar de las mayorías; con el paso del tiempo, también los socialistas llegaron a ser elegidos. En Cataluña, los nacionalistas lograron enviar una representación significativa al Congreso de Madrid. Pero, esta representación de las oposiciones al sistema, basadas en movimientos reales de opinión, se perdía irremediablemente en el conjunto nacional. Sobre unos 400 escaños del Congreso, el máximo número de diputados republicanos fue 36 en 1903, y el de diputados socialistas fue 7 en 1923. No es preciso recordar que, incluso en 1931, las elecciones las ganaron los monárquicos en números absolutos, aunque el triunfo republicano en los principales núcleos urbanos del país, resultara definitivo para la valoraciń final de los resultados. Los diputados, por otra parte, siguieron siendo, más o menos, los mismos: abogados, propietarios, políticos profesionales y, en menor número, representantes de profesiones liberales. La aplicación del sufragio universal no supuso el acceso al poder legislativo de nuevos grupos sociales, salvo contadas excepciones.

La explicación de esta continuidad en los resultados y en la clase políti$\mathrm{ca}$, radica, por una parte, en algunas características de la ley electoral, pero, sobre todo, en la condición social de los nuevos electores. En efecto, la ley de 1890 ampliaba el derecho electoral a todos los varones mayores de 25 años, al tiempo que reconocía la posibilidad de un voto orgánico, corporativo, que habría de tener muy poca importancia; pero no variaba la entidad de las unidades electorales establecida por la ley conservadora de 1878 . Esta ley distinguía entre distritos uninominales, exclusivamente rurales, y circunscripciones, que elegían un número de diputados proporcional a sus habitantes, entre tres y ocho, compuestas por población urbana y rural, pero de for- 
ma que ésta era mucho más numerosa, pudiendo así sofocar con facilidad, en muchos casos, el voto urbano, más difícil de controlar. La posible evolución del electorado más sensible a los cambios sociales, quedaba de esta manera sin reflejo en los resultados electorales, aunque, en cierta medida, no quede oculta al investigador que tenga acceso al resultado de la votación por secciones. En este aspecto, los liberales de 1890 no recuperaron la legislación de los revolucionarios del 68 , que reconocía la personalidad electoral de las pequeñas ciudades, capitales de provincia, sino que respetaron la legislación conservadora.

Sin embargo, el factor explicativo más importante de la falta de consecuencias de la aplicación del sufragio universal, respecto a los resultados electorales y a la clase política $-\mathrm{y}$, por supuesto, respecto también a la acción política de los gobiernos- es la condición social de los nuevos electores. La mayoría, masculina, del país a quien se había concedido el voto, no estaba compuesta por clases medias y trabajadoras de carácter urbano, con planteamientos políticos relativamente determinados, sino por clases rurales -jornaleros, pequeños propietarios-completamente ajenas a cualquier proyecto político de carácter nacional $-y$ mucho menos de contenido liberal democrático- cuya pasividad sólo se alteró en contadas ocasiones; una mayoría en la que predominaban la pobreza, el analfabetismo y la visión tradicional de la vida, que fue fácilmente integrada en las redes caciquiles.

Pero el «caciquismo» no podía seguir siendo lo mismo. El hecho de que aparentemente no hubiera cambiado nada, no quiere decir que todo siguiera siendo igual. La nueva ley había variado sustancialmente el número de participantes y también las características de los mismos. En la anterior situación, de sufragio censitario, hemos concluido que el caciquismo consistía, previsiblemente, en la mayor parte de los casos, en la influencia individual sustentada sobre una clientela a la que se satisfacía con el ejercicio arbitrario de la ley, y hemos señalado el predominio del acuerdo y el consentimiento sobre la coacción y la violencia, entre los participantes. La situación creada por el sufragio universal hacía mucho más difícil el funcionamiento de este mecanismo, porque multiplicaba por seis el número de los que debían ser beneficiados, sobre todo considerando que los recursos políticos disponibles eran escasos, dado que, a fines del siglo XIX, estamos muy en los comienzos del Estado interventor en España. En cualquier caso, la nueva ley introducía nuevos factores o multiplicaba su importancia, en la medida que estos factores estaban presentes en la nueva mayoría política: el peso de la deferencia hacia las jerarquías tradicionales, de la aceptación del orden social, la vulnerabilidad ante el poder económico, la indiferencia respecto a la política. Algunos son factores de tipo cultural, relativamente desatendidos por las recientes interpretaciones del caciquismo - que se han ocupado, en especial, de 
la dimensión económica y política del fenómeno- pero que también es preciso tener en cuenta para poder explicarlo. La mayor parte de la sociedad rural española de fines del siglo XIX, estaba dominada por una concepción tradicional de la vida, con un fuerte componente religioso, y es un lugar común afirmar que esta mentalidad es «el más poderoso de los factores adversos a la acción política izquierdista de los trabajadores y campesinos pobres» (5). La extensión alcanzada por la compra de votos y la indiferencia que la mayoría sentía por la política están fuera de toda discusión.

Por tanto, la ley de sufragio universal debilitó la base clientelar sobre la que se asentaba el funcionamiento del sistema electoral en el período anterior, aumentando sus componentes de corrupción y violencia. Por otra parte, no supuso una mejora del sistema representativo, mediante el fortalecimiento de los partidos que apelaban a la opinión y a los intereses de grupos sociales determinados; los pequeños avances conseguidos en este sentido fueron neutralizados, además de por la distribución territorial de los escaños - por el ahogamiento del voto urbano con el voto rural-, por el peso de la abrumadora mayoría gubernamental.

Hay un testimonio contemporáneo que atribuye al sufragio universal la principal responsabilidad de la corrupción política que no me resisto a dejar de transcribir. Es la contestación del conservador catalán J. Mañé y Flaquer al cuestionario de Joaquín Costa. «Opino que la causa principal, si no la única, del grande desarrollo que han tomado en España la oligarquía y el caciquismo, no es otra que la implantación del sufragio universal, que el pueblo no pedía, ni quería, ni deseaba. Desilusionada la clase proletaria por el fracaso de la República, de la cual no sacó ventaja alguna, apartose en absoluto de la política, y hoy no se ocupa más que en procurarse aumento de jornal y disminución de horas de trabajo, por medios propios y con entera independencia de los partidos. La clase media no acude a las urnas, a pretexto de que está desengañada de la política. $Y$ como a todo esto, los políticos que explotan el parlamentarismo continúan pidiendo elecciones, ha habido necesidad de acudir a empresarios que se encarguen de simularlas con electores ficticios, ya que los verdaderos se mantienen retraidos (...) El sufragio universal lo debemos, pues, no al irresistible anhelo de la masa popular, ni a la convicción profunda de las clases más ilustradas, sino a componendas de la ambición de partido. Su ejercicio ha sido una escuela constante de desmoralización para todas las clases sociales, demostrando que eran ciertos los defectos que Sagasta y Cánovas le habían atribuido; pero nadie se atreve a poner la mano en esta gran conquista de la democracia española; iy sigue la farsa!» (6).

J. Pitt-Rivers ha señalado una evolución en el caciquismo relativamente semejante a la que hemos apuntado, desde una especie de patronazgo en 
la que «el rico emplea, asiste y protege al pobre, quien a su vez trabaja por aquél, le da estima y prestigio, y también protege su interés procurando que no sea robado, advirtiéndole de las maquinaciones de los otros, y poniéndose de su parte en las discusiones», "una amistad desequilibrada en la que el elemento de simpatía no está excluido en absoluto», a otra especie de patronazgo en la que «la apariencia de amistad es usada para ocultar un arreglo puramente venal, el uso del dinero por parte de un hombre rico para alcanzar sus fines», «En el primer período - escribe Pitt-Rivers-cacique parece haber significado no más que una persona de prestigio local, y se encuentra a un joven en una novela de Juan Valera (Pepita Jiménez, 1873) que se enorgullece de que su padre sea el cacique del pueblo, mientras que, al final de su curso, llegó a ser un término de oprobio que designa al corruptor, a quien soborna y emplea al matón (Cf. Pío Baroja, César o nada, 1922)» (7).

No quiero entretenerme más que brevemente considerando qué habría sucedido si, en lugar de producirse la aprobación del sufragio universal, hubiera continuado existiendo el sufragio censitario. Los movimientos nacionalistas - factores positivos de movilización política - no parece que hubieran sido afectados negativamente, dada la base burguesa sobre la que principalmente se asentaban; en todo caso habrían salido beneficiados. Desde luego, a las oposiciones al sistema - republicanos y socialistas - no parece que pudiera haberles ido peor, dada la exigua representación que obtuvieron con la nueva norma. Quienes, por el contrario hubieran salido beneficiados, probablemente, eran las tendencias renovadoras dentro de los partidos turnantes, al encontrar un apoyo efectivo en la opinión pública, o partidos como el reformista que no hubieran tenido que refugiarse en el encasillado para disponer de una pequeña representación en el Congreso. $Y$, probablemente, si el régimen parlamentario hubiera terminado cayendo, no lo habría hecho con los caracteres de corrupción que terminó adquiriendo.

La última conclusión que cabe sacar es que el sufragio universal, tal como se aplicó en España, no fue un factor positivo para la modernización política del país. No impulsó la transformación de la estructura de los partidos, ni fortaleció en la medida suficiente el papel de la opinión pública en la vida política. Por el contrario, aumentó los componentes de corrupción y violencia del sistema y frustró las tendencias renovadoras del mismo.

Afirmar lo anterior coincide, por supuesto, con las tesis conservadoras. Tanto con las de quienes veían en él un medio para asegurarse el control político -como Napoleón III, por ejemplo, que en 1861 aconsejó al gobierno prusiano la introducción del sufragio universal «mediante el cual, la población rural conservadora podría superar en número de votos a los liberales de las ciudades" - como con las de Cánovas o Francisco Silvela, que sinceramente 
lo consideraban inaplicable en un país de la estructura social de España a fines del siglo XIX. Pero no sólo los conservadores opinaban así. Proudhon escribió que, en la Francia de 1848, «el sufragio universal es la contrarrevolución» y el resultado de las elecciones de abril y diciembre de aquel año le dieron la razón. Y Bakunin se expresó en el mismo sentido, en 1871, afirmando los efectos reaccionarios que se derivarían del ejercicio del derecho de voto por una mayoría de la población que no era independiente económicamente y que no disponía de ocio y educación para poder ocuparse y entender las cuestiones políticas (8).

(1) El proyecto de Cánovas y su lucha contra los moderados, en J. Vareia Ortega, Los amigos políticos, Madrid, 1977, pp. 22-134.

(2) Vid. C. Dardé Morales, "Las elecciones de diputados de 1886». Anales de la Universidad de Alicante. Historia Contemporánea 5 (1986) 223-259.

(3) J. Romero Maura, «El Caciquismo» en J. Andrés-Gallego (Coord.), Revolución y Restu. ración 1868-1931. Madrid, 1981, vol. 2, pp. 71-88. J. Varela Ortega, op. cit.

(4) Esta parte recoge en buena medida mi artículo «La implantación de la democracia er la España de la Restauración». Revista de Occidente 50 (junio, 1985) 115-126.

(5) S. M. Lipset, El hombre politico. Las bases sociales de la política. Buenos Aires, 1977 p. 244 .

(6) En J. Costa, Oligarquía y caciquismo como la forma actual de gobierno en España. Madrid, 1902, pp. 291-292.

(7) J. Pitt-Rivers, The people of the Sierra. Chicago, 1971, pp. 140-141.

(8) Frase de Napoleón III, citada por S. M. Lipset, op. cit., p. 266. P. J. Proudhon, Idea general de la Revolución en el siglo XIX. Citado por M. Bakunin, Escritos de filosofía política. Compilación de G. P. Maximoff. Madrid, 1978, vol. 1, p. 265. M. Bakunin, op. cit., pp. 264-266. 